\title{
50 AÑOS DE LA GESTA HUANTINA POR LA GRATUIDAD DE LA EDUCACIÓN
}

\author{
50 YEARS OF THE HUANTINE DEED FOR THE GRATUITY OF \\ EDUCATION \\ (DD)Edgar Gutiérrez Gómez ${ }^{*}$ \\ egutierrez@unah.edu.pe \\ ${ }^{1}$ Universidad Nacional Autónoma de Huanta, Ayacucho, Perú
}

*Correspondencia: Edgar Gutiérrez Gómez. Email: egutierrez@unah.edu.pe

Recibido: 09.06.19 | Aprobado: 22.06.19

\section{RESUMEN}

La gesta huantina de hace 50 años por la restructuración de la gratuidad de la enseñanza, en razón al Decreto Supremo 006 de 1969, durante el gobierno militar de Juan Velasco Alvarado, fue un hecho luctuoso su derogatoria, en este desenlace participaron activamente los estudiantes de secundaria, campesinos y población en su conjunto. Huanta fue un escenario especial para su derogatoria, hasta la actualidad existen sobrevivientes de esa lucha por la educación. La historia oficial dejó de lado la actuación del poblador huantino de hace 50 años por reivindicar la educación pública en el Perú, la Reforma Agraria y Día del Campesino decretado por el gobierno militar, socavó las luchas por la educación. Este 2019 se conmemora los 50 años de la gesta huantina por la gratuidad de la educación.

Palabras clave: Gesta huantina, gratuidad de la educación, Decreto Supremo 006.

\section{ABSTRACT}

The huantine feat of 50 years ago for the restructuring of the gratuity of education, by reason of the Supreme Decree 006 of 1969 of the military government of Juan Velasco Alvarado, was a sad fact its derogatory, in this denouement the high school students actively participated, peasants and the population as a whole. Huanta, it was a special scenario for its repeal, to this day there are survivors of that struggle for education. The official story left aside the performance of the Huantine villager 50 years ago to claim public education in Peru, the Agrarian Reform and Farmers' Day decreed by the military government, undermined the struggles for education. This 2019 is commemorated the 50th anniversary of the huantine deed for the gratuity of education.

Keywords: Gesta huantina, gratuity of education, supreme decree 006. 


\section{INTRODUCCIÓN}

El presente trabajo es una investigación bibliográfica enmarcada en un escenario adverso a la situación vulnerable que se vive aún, después del informe final de la Comisión de la Verdad y Reconciliación (CVR), puesto que su contenido no necesariamente refleja la verdad contextual. La situación social de la región de Ayacucho es tergiversada con dos hechos históricos de trascendencia nacional como es la lucha social por la derogatoria del Decreto Supremo 006 de 1969 dispuesto en el gobierno militar de Velasco Alvarado, el cual estableció un pago por repitencia de cursos. El otro escenario que se manifiesta es una genealogía de convulsiones sociales dirigida por el movimiento armado sendero luminoso que declaró una guerra interna al Estado peruano. Este escenario es malinterpretado por la sociedad civil como una manifestación inmediata del descontento social manifiesta en 1969 por estudiantes secundarios y campesinos en defensa de la gratuidad de la educación.

El trabajo de investigación está enmarcado en función a las fuentes bibliográficas que se han encontrado con diversas aristas para sistematizar dicha información. El propósito del trabajo no es realizar una historiografía minuciosa sin análisis crítico del contexto de la época y los escenarios actuales de los movimientos sociales, sindicatos como radicales en contra del gobierno de turno. Son fenómenos ocurridos en un contexto determinado con las condiciones y necesidades de factor social interviniente.

\section{CAMPESINOS POR LA GRATUIDAD DE LA EDUCACIÓN}

Una de las características más esenciales del poblador huantino es la identidad local de "nacionalismo irónico" que semienta su orgullo ciudadano. El escenario es propicio para que su poblador manifieste estremecimiento por su territorio que le dio estatus quo, es bien acertada la referencia estricta del academicismo actual: "¿Sucede que cuando alguien pronuncia la palabra territorio o el término región, no hay quien diga "terri...qué?" o "regio...qué"; Son términos por demás comunes y corrientes”. (García, 2002, p.201). El ciudadano del mundo fomentado por los estoicos y refinado por la filosofía existencialista no deja margen de error sobre los conceptos estandarizados de territorio y región para suministrar su lugar a esa idiosincrasia de identidad huantina. El etnocentrismo cultural que hace singular a sus pobladores es un aliciente de identidad local al resto de las provincias que templó su construcción de orgullo regional. Este 22 de junio del 2019 se cumple 50 años de movimiento popular de estudiantes secundarios y campesinos en contra de:

El Decreto Supremo 006-69/EP perjudicaba visiblemente a los alumnos provenientes de estratos populares, en tanto establecía el pago de S/.100 mensuales (aprox. U\$2,30), cifra bastante elevada, especialmente para los padres de familia de las zonas rurales andinas". (Degregori, 2011, p,51).

Algunos ciudadanos que vivenciaron el escenario contextual de la lucha en su época, rumorean discretamente en sus círculos sociales sobre el acontecimiento que situó a Huanta en la escena nacional de lucha por la gratuidad de la educación. En su época ninguneados con el único propósito de minimizar el fenómeno nacional, priorizando la 
reforma agraria como bandera demagógica para el campesinado en el Perú de 1969. No se puede olvidar la memoria honorable de las víctimas como afirma

Ricardo Dolorier: "Cuenta que se reunieron cerca de diez mil personas entre profesores, escolares y campesinos y marcharon a la plaza de Huanta". (La República, 2009).

El acontecimiento trascendental que desafío al estado peruano en un período de régimen castrense de gobierno militar, nada menos; es un fenómeno social que debe referenciar los anales de la historia de la educación peruana. Como establece Degregori: "Pero luego de los levantamientos de Huanta y Ayacucho, parte del Decreto Supremo 006 (DS-006) fue derogado en sus partes esenciales". (2011, p.52). Como es de conocimiento público a la razón popular, el poder de turno busca escenas teatrales que acapare la notica importante. Es así, al mismo tiempo de la derogatoria del DS-006, se decreta la Reforma Agraria instituyendo el 24 de junio como el día del campesino. Reforma aceptada de buen agrado por el campesinado en desmedro de los terratenientes y hacendados afincados en el territorio peruano, producto del rezago colonial.

El Gobierno Revolucionario de las Fuerzas Armadas se inició en el año 1968 luego del golpe de Estado realizado al presidente Belaunde. Este gobierno de facto es muy conocido por llevar a cabo la reforma agraria y la nacionalización de sectores estratégicos como los recursos o los medios de comunicación. Lo que no es muy recordado es lo ocurrido en el año 69. (Rojas, 2010).

El tratamiento del indio, será resanado en algo para dar paso a la eliminación del racismo impregnado por los verdugos españoles. El Día del Indio decretado por Augusto B. Leguía en 1930 para su celebración cada 24 de junio es reemplazado: "El 24 de junio de 1969, cuando el presidente Juan Velasco Alvarado promulgó la Ley de Reforma Agraria cambió también la denominación del Día del Indio por el Día del Campesino” (2015). Paradójicamente, los padres de familia campesinos asentados en las partes altas de Huanta, fueron los luchadores por la gratuidad de la enseñanza. Las organizaciones populares para la afrenta a las fuerzas del orden se establecieron: "Se forman columnas: en primera línea marchan los chutos, campesinos quechuas de las punas, portando banderas; les siguen las mujeres y estudiantes detrás la masa de campesinos". (Degregori, 2011, p.62). Al margen de las rótulas racistas hace 50 años, actualmente quedan resquicios de la tara feudal del gamonalismo socavado por el movimiento armado de sendero luminoso en los lugares de los chutos referenciado por Degregori. Los efectos colaterales tienen basto conocimiento el poblador peruano, pues muchas veces abanderados de la pacificación terminan terruqueando al poblador andino.

\section{ESTUDIANTES DE SECUNDARIA EN LA PALESTRA DE HUANTA}

La mayoría de edad como ciudadano en muchos países del mundo se adquiere a los 18 años de edad, cronología insuficiente para aquellos conservadores y arcaísmo para los liberales. Nuestros adolescentes, de hoy, están encapsulados en la era digital o son obreros digitales ajenos a su entorno real, inmersos a la adicción narcótica del universo postmoderno. Es importante señalar, jamás ocurre un fenómeno para volver al pasado, añorando la educación de nuestra época, mejor apelemos que: "Todos trabajamos para 
Facebook o para Google. Cuando usas el buscador, generas un rastro, produces algo y eso es trabajo. Y luego sus algoritmos, producidos por humanos, se utilizan para anticipar tu comportamiento y el de los demás, para ganar dinero con tu trabajo". (Gabriel, 2019). El contexto digitado por los algoritmos que adivinan lo que necesitamos y, los adolescentes convertidos en zombis interconectados en el mundo digital, difícilmente logrará una lucha estudiantil a imagen y semejanza de hace 50 años. Emitir un comunicado ante un fenómeno adverso de crisis ideológica en condición de estudiantes secundarios de principios neutrales es colosal como, por ejemplo, sobre la participación de una mujer lideresa en educación secundaria:

El 23/09/1982, el Comité Coordinador y Unificador del Movimiento Estudiantil Secundario (CCUMES) expresó sus condolencias por la muerte de Edith Lagos, militante senderista e integrante del CCUMES en sus años escolares, asimismo, encabezó las luchas contra el alza del pasaje escolar y la derogatoria de la nota aprobatoria 12, en el departamento de Ayacucho. (Publicado por diario El Diario) (APRODEH, 2017).

Los adultos como padres de familia buscando que los hijos sean modernos, pero más luego recriminan a esos adolescentes millennials que no soportarían par de minutos sin internet en su vida diaria. El problema por la gratuidad de la educación que involucró a los padres de familia a nivel nacional, pronto salpica a poblaciones más pequeñas y su organización se hace más cohesionado y efectiva. Es así, en Huanta la población se organiza para exigir la derogatoria del DS-006 en un cabildo abierto, al mismo tiempo en Ayacucho el Frente de Defensa envía un memorial al Presidente de la República, exigiendo su derogatoria. En este escenario confuso y de incertidumbre en Huanta, se gesta una acción que señala como un condicionante Degregori:

Pero hacia fines de mayo se agudiza el ausentismo escolar y los estudiantes comienzan a organizarse, especialmente en Huanta, donde un grupo de jóvenes militantes de izquierda se reúne en secreto. De pronto, la sorpresa: el domingo $1 \mathrm{de}$ junio se constituye el Frente Único de Estudiantes de Huanta (FUEH). (2010, p,57).

La fundación de organizaciones de lucha social es característica esencial de los jóvenes universitarios o agremiados de trabajadores, en este caso es un aspecto importante de estudiantes de Educación Secundaria, la que hoy se denomina Formación Básica. Sin embargo, como en todas las luchas sindicales o gremiales, siempre existen los denominados "amarillos" o que se identifican con las normas establecidas por un gobierno. En este contexto ocurrió que el Director de la Gran Unidad Escolar "Gonzales Vigil” expulsó a los estudiantes que no pudieron pagar su mensualidad, estos antes de quejarse a sus padres -como ocurre hoy-, al día siguiente, ingresaron a la fuerza al colegio para azuzar a sus compañeros para su apoyo en la lucha. El mito fundacional es presente en diferentes luchas sociales a lo largo de la historia de la humanidad: "En ocasiones la violencia presenta a los hombres un rostro terrible; multiplica enloquecidamente sus desmanes; otras, al contrario, se muestra bajo una luz pacificadora, esparce a su alrededor los beneficios del sacrificio”. (Girard, 1983, p,44). Este constituiría un apunte para el 
compromiso de toda una población quechua hablante, campesinos analfabetos ofrendarán sus vidas en apoyo a los estudiantes que luchan por su educación.

El fenómeno trascendió a nivel nacional, logrando que el gobierno militar retroceda en su afán de privatizar la educación popular en el Perú. El mito de la teoría fundacional que la historia de la educación peruana registrara, fue sustituido con la reforma agraria declarada el 24 de junio y, su consecuente instauración como día del campesino. El principal argumento después de la derogatoria del Decreto Supremo 006, las vinculaciones directas con los movimientos armados de Sendero Luminoso fueron sugerentes con visos de seguridad en la participación activa, como indica Mario Cavalcanti: "Todos estos hechos se pretendieron vincular con el PC-SL, pero el accionar violentista de este grupo político se inició 11 años después, en las elecciones generales de 1980, en Chuschi con la quema de ánforas electorales". (Retablo, 2009, p,17). Las vinculaciones con los movimientos de izquierda a nivel internacional, nacional y local no estuvieron ajenas para justificar la imposición de la fuerza de los gobernantes de turno.

\section{MUJERES EN LA LUCHA REIVINDICATIVA}

Las memorias de la historia reconocen el matriarcado como forma de familia establecida, la historia se encomendó a socavarla. Engels en su importante trabajo al respecto fundamenta, que: "Antes de pasar a la monogamia, a la cual da rápido desarrollo el derrumbamiento del matriarcado, digamos algunas palabras de la poligamia y de la poliandria”. (2017, p,24). En la historia de la humanidad son incompletos los registros a las mujeres como seres humanos iguales a los varones, elucubraron filósofos misóginos como Artur Schopenhauer: "Las mujeres perjuran ante los tribunales con mucha más frecuencia que los hombres, y sería cuestión de saber si debe admitírselas a prestar juramento". (2003, p,71). La actualidad demuestra cierta relación con el planteamiento de Schopenhauer, puesto que, la situación moderna está atiborrada de juicios y leyes a favor de las mujeres, independientemente de la masa popular luchadora. Los movimientos por la reivindicación de la mujer en la historia de la humanidad, por concretar su posicionamiento, fue una lucha dificultosa, pues en el proceso de la búsqueda de libertad en iguales condiciones sucedieron luchas muy peligrosas y sacrificadas. La adquisición de la ciudadanía para las mujeres peruanas fue tardía a diferencia de los países vecinos de Sudamérica:

El 7 de setiembre de 1955, el presidente de entonces, Manuel A. Odría, firmaba y promulgaba la ley 12391 que incluía la siguiente modificación a la Constitución: Artículo 84: Son ciudadanos los peruanos varones y mujeres mayores de edad, los casados mayores de 18 y los emancipados. (García, 2018).

El estado peruano concibe el reconocimiento como ciudadana a las mujeres, siempre secundando al analfabetismo que campea aún, actualmente, en los sectores más alejados a la metrópoli, pues Lima es la panacea de la modernidad. La educación machista, dentro del hogar, sigue cobrando rezagos precoloniales. El derecho al voto y ser elegido estaba permitido para las alfabetizadas en un escenario de predominio machista. Finalmente, en 1979 se logra el derecho al voto universal con la inclusión de las mujeres analfabetas, participando en las elecciones de 1980. En la mayoría de las religiones oficiales 
del mundo, las mujeres son y fueron secundadas en razón a la masculinidad, hasta en sus rituales, por ejemplo:

"Uno de los más conocidos tabúes primitivos, el que tal vez ha hecho correr más tinta, se refiere a la sangre menstrual. Es impura. Las mujeres que menstrúan son obligadas a aislarse. Se les prohíbe tocar los objetos de uso común, y en ocasiones hasta sus propios alimentos que podrían contaminar..." (Girard, 1983, p,40).

Los registros históricos dan cuenta que la lucha por la reivindicación femenina fue legislada por varones de acuerdo a su posición de género. Pocos pasajes de la Biblia y demás libros considerados sagrados, que rigen una religión oficial, atienden al varón detrás de las mujeres. La historia de la filosofía y demás áreas de estudio mantienen en el anonimato la labor académica de las mujeres. Huanta fue un escenario adverso y de ejemplo para otras partes del territorio peruano en la lucha popular por la gratuidad de la educación, mujeres campesinas como el caso de la jornada sangrienta en Huanta: "De entre ellas se adelanta una anciana campesina para parlamentar con la policía. Tensión y silencio. Invocando la cordura, con los brazos en alto, la campesina avanza, pero una ráfaga de metralla la derriba”. (Degregori, 2010, p,63). La historia oficial en el Perú, siempre fue escrita por los ganadores o en su defecto por los que ostentan poder de turno. Es así, que la historia peruana no registra la gesta huantina por la gratuidad de la educación de 1969, menos en la historia de la educación peruana. Independientemente al predominio masculino del acceso a la educación y las luchas sociales, en Huanta la manifestación fue que: "El colegio religioso femenino "María Auxiliadora" no se pliega a la huelga; sin embargo, un grupo de alumnas colabora clandestinamente con el movimiento". (Degregori, 2010, p,58). La historia universal absuelve las dudas al respecto; puesto que, las luchas reivindicativas de la población con menos acceso al poder, tiene bases femeninas en su disputa por conquistar colaborando activamente en forma anónima.

En las épocas reivindicativas de la mujer actual, se cumplen los 50 años de la gesta huantina por recuperar la gratuidad de la educación en un gobierno militar; años de lucha donde aún persisten escenarios de la educación secundaria o formación básica de la educación peruana con exclusividad para mujeres. Instituciones educativas aún regentadas por congregaciones religiosas, diseñados especialmente para mujeres. Así se manifiesta un sexismo legalizado por el Estado peruano y el Ministerio de Educación. Afortunadamente, el escenario actual exige la igualdad de género, donde la heterogeneidad cultural en un colegio mixto hace que exista la atmósfera de trato horizontal entre pares y adultos. Los movimientos sociales reivindicativos en el mundo, por lo general, se asocian a la izquierda política, así como la vida de la activista femenina Simone de Beauvoir:

Por la vastedad de sus miras, Simone creó una imagen diversa, múltiple y cambiante que no han conseguido superar otras escritoras contemporáneas: viajó, enseñó, experimentó, discutió, escribió y comenzó a publicar a los treinta y seis años de edad, participó en las actividades políticas más connotadas de la izquierda y mantuvo un ojo siempre en alerta frente a los cambios. (Robles, 2002, p,107).

Imaginar una referencia única a Simone de Beauvoir, sería un error en el contexto de las luchas sociales en el mundo con ribetes revolucionarios, relacionados a otras mujeres anónimas que dieron su vida en la lucha por la gratuidad de la enseñanza hace 50 
años en la provincia de Huanta. Sobre la importancia de la figura filosófica de Simone de Beauvoir al lado de Jean Paul Sartre, resulta inusual ejemplo de una vida libre para el contexto donde le tocó vivir: "Hasta el final, dedicó sus días a militar en favor de los derechos de las mujeres, los viejos, los judíos, los negros, los colonizados. (Audero, 2014, p,156).

Nuestra sociedad actual vive un fenómeno sensible de la defensa femenina por diferentes flancos, desmereciendo algunas veces la labor masculina, reduciendo a un sector marginal de lumpen. El compositor que inmortalizó la lucha social huantina de 1969 a través de la canción titulada "Flor de retama" es Ricardo Dolorier, esta se canta hasta la actualidad en los escenarios de evocación de la gesta huantina. Cuando se cumplió los 40 años de la popular canción, Dolorier afirmó sobre la interpretación de su letra en siguientes términos: "Sí, Martina fue muy importante para la difusión de "Flor de retama", pero su temperamento va en contra de la melodía. Josefina Ñahui es al revés, la melodía se impone al temperamento de la canción. A mi modesto juicio, quien la canta bien es Edwin Montoya". (La República, 2009). La cantante folklórica e investigadora de la cultura andina Leonela Martina Portocarrero Ramos es la que conecta más con la población cantando las letras de la canción "Flor de retama" himno inolvidable e identificable de la gesta huantina, conocida en el escenario nacional e internacional como insurgencia hacia el Estado peruano.

Las protestas por la derogatoria del Decreto Supremo, fueron desarrollados por un sin número de estudiantes de educación secundaria, teniendo en cuenta la participación activa de las mujeres estudiantes de su época contraviniendo las normas morales del machismo reinante. El escenario del terruqueo que se vive en el sistema actual de cuestionamientos, amenazas constantes, donde las mínimas protestas de reivindicación en masa son atribuidas a resurgentes senderistas. La masa que se encuentra dentro de una estratificación social menospreciada en el sistema piramidal, se inhibe a manifestar su opinión en forma libre por temor a ser sindicato como agitador. Al margen de las interpretaciones de libre opinión y pensamiento moderno, está la escolar de secundaria, Edith Lagos que pasó rezagada en la historia de la gesta huantina por sus vinculaciones a sendero luminoso en las décadas de los '80:

La Huamanga que vive Edith Lagos en su adolescencia es parte de ese gran escenario de movilización social, popular y nacional, que caracterizó los años setentas del siglo pasado. Tal como Carlota Tello y centenas de jóvenes, ella también participó en las luchas estudiantiles contra las reformas en la escala de calificación escolar, cuya violencia y convocatoria tuvo un fuerte impacto regional a fines de la década de 1970. (Caro, 2005, p,11).

Cada contexto histórico es diferente a los demás, muchas veces la sociedad juzga sin diferenciar el escenario en su contexto real, así lo corroboran el materialismo dialéctico e histórico, como el desarrollo de la sociedad en su conjunto. En esta consideración el liderazgo social se cultiva desde las tempranas etapas del desarrollo humano, así está demostrado en las luchas reivindicativas de la población huamanguina, durante su historia. La figura social de líder adolescente de Edith Lagos fue secundada por su accionar y vinculación en los escenarios del movimiento armado de sendero luminoso. Como el 
contexto actual es sensible a los temas de movimientos sociales, la figura de Lagos no se comprende en los anales de la lucha por la gratuidad de la educación peruana en Huanta y Huamanga. El desenlace de la luchadora social por la gratuidad de la educación tiene aspectos distintos a la naturaleza reivindicativa, independiente a las especulaciones del terruqueo que sí vive Ayacucho y el Perú: "La multitudinaria asistencia al funeral, que fue oficiado por un obispo, y al entierro de la dirigente de la organización guerrillera Sendero Luminoso, Edith Lagos, que tuvo lugar en la ciudad sureña de Ayacucho, ha despertado preocupación en la clase dirigente peruana". (El País, 1982). La costumbre del pensamiento por sentido común no es científica, desafía los cánones de la ciencia lógica del positivismo. Un fenómeno ocurrido en un contexto determinado no es principio inicial de un pensamiento científico, entonces es importante diferenciar cada escenario de la historia para poder juzgar con crédito adecuado. La situación de conflictiva marginación fue espacio suficiente para que sendero luminoso aprovechara la coyuntura con el pensamiento marxista de su época: "Es interesante resaltar cómo Sendero supo sacar provecho de los sentimientos de exclusión, discriminación y resentimiento originados en las tensiones de carácter étnico y de clase que se producían en una sociedad estamental como la ayacuchana, que eran mucho más difíciles de sobrellevar entre las jóvenes". (Huber, 2003, p, 161). Estas investigaciones explican la rebeldía innata de las mujeres en Ayacucho, pero sin establecer sexismos en su época contextual y actual de la vulnerabilidad misógina.

\section{CONCLUSIÓN}

A manera de conclusión se puede indicar que existen fuentes diversas sobre los sucesos acaecidos en junio de 1969, en un gobierno militar, aceptado como un gobierno ejemplar para los campesinos no involucrados en la lucha de la gratuidad de la educación. La importancia trascendental de esa lucha social en favor de la educación gratuita fue oscurecida por la reforma agraria de Velasco, abanderado sistema para los campesinos. Sin embargo, los testimonios vivos de aquella gesta huantina, aún sobreviven para manifestar lo vivido en su etapa de la adolescencia escolar. Que difícilmente podemos equiparar con la educación actual de las luchas sociales de estudiantes secundarios.

Es escenario también manifestar que aquella época fue aún, enlodado con el movimiento armado de sendero luminoso, como colofón del caos vivido por los campesinos de Huanta y Ayacucho, involucrando la lucha a nivel nacional. La investigación y composición de la letra de la canción "Flor de Retama" de Ricardo Dolorier fue tergiversado, por la población poco informada, como himno que caracteriza las protestas sociales inmiscuidas con sendero luminoso. Esta afirmación, es totalmente falsa por la poca información y masificación del hecho histórico huantino en el escenario nacional e internacional. La educación pedagógica es determinante para su conocimiento objetivo de la realidad como se indica: "La pedagogía no tendría sentido aparentemente, pero tiene un poder inmenso dentro del aparato social de la formación de ciudadanos". (Gutiérrez, 2017, p.7). Por tanto, es indispensable que el ciudadano común sepa la información de los hechos históricos fidedignos acaecidos en un contexto determinado, además de que estos acontecimientos vivan dentro de la memoria colectiva. 


\section{REFERENCIAS BIBLIOGRÁFICAS}

APRODEH, (2017). Estudiantes secundarios expresan pesar por la muerte de Edith Lagos. Publicado el 09 de febrero. (28-05-19). https://cutt.ly/NHaXLrx

Arturo, S. (2003). El amor, las mujeres y la muerte. Retrieved from https://ebookcentral.proquest.com

Audero, G. (2014). Bocaditos en palabras. Retrieved from https://ebookcentral.proquest.com

Carbajosa, A. (2019). Entrevista. "Silicon Valley y las redes sociales son unos grandes criminales". Publicado el 1 de mayo. (07-05-19) https://cutt.ly/5HaXHvX

Caro, C. R. (2005). Ser mujer, joven y senderista: género y pánico moral en las percepciones de Sendero Luminoso. Digitalizado. (28-05-19). https:// cutt.ly/NHaXDbO

Cavalcanti, M. (2009). 21 y 22 de junio de 1969: Las protestas por la gratuidad de la enseñanza en Ayacucho. Retablo Año 4, No 27. Ayacucho.

Cultura y desarrollo regional. (2002). Retrieved from https://ebookcentral.proquest.com Degregori, C. I. (2010). El surgimiento de Sendero Luminoso. Ayacucho 1969 - 1979 del movimiento por la gratuidad de la enseñanza al inicio de la lucha armada. Instituto de Estudios Peruanos, IEP.

El País, (1982). Duelo multitudinario en el entierro de una dirigente guerrillera peruana. Publicado el 15 de setiembre. (04-06-19). https:// cutt.ly/ZHaXX7w

Engels, F. (2017). El origen de la familia, la propiedad privada y el estado. Esta edición digital: Archivo Marx-Engels de la Sección en Español del Marxists Internet Archive (www.marxists.org).

García, O. (2018). Histórico: asi fue el día en que se otorgó derecho al voto a la mujer peruana. Publicado el 10 de setiembre. (24-05-19). https://cutt.ly/iHaXN9K

Girard, R. (1983). La violencia lo sagrado. Barcelona. Editorial Anagrama.

Gutiérrez, G. E. (2017). Pedagogía como acto de amor frente al panoptismo de Foucault. Kuntur Año 5, No 5. Ayacucho.

Huber, L. (Ed.). (2003). Centralismo y descentralización en Ayacucho. Retrieved from https://ebookcentral.proquest.com

La voz de los emprendedores. (2015). Publicado el 23 de junio. (07-05-19). https://www.pqs.pe/economia/dia-del-campesino-como-surgio-esa-celebracion

La República (2009). "Flor de retama me salió de adentro". Publicado el 06 de noviembre. (2505-19). https://larepublica.pe/tendencias/431055-flor-deretama-me-salio-deadentro

Robles, M., \& Robles, M. (2002). Mujeres del siglo XX. Retrieved from https://ebookcentral.proquest.com 
Rojas, S. C. (2010). La plazuela de Huanta. Publicado 01 de setiembre. (25-05-10). https://lamula.pe/2010/09/01/la-plazuela-de-huanta/cristhianrs/

\section{CITAR COMO:}

Gutiérrez Gómez, E. (2019). 50 años de la gesta huantina por la gratuidad de la educación. Puriq, 1(01), 33-42. https://doi.org/10.37073/puriq.1.01.58 